\title{
A UTILIZAÇÃO DE DINÂMICAS PARA O ENSINO EM ENGENHARIA: UM RELATO NA ENGENHARIA DE PRODUÇÃO
}

LucianaTCMello-luciana.mello@ufersa.edu.br

Universidade Federal Rural do Semiárido - UFERSA

Centro Multidisciplinar de Angicos, Departamento de Engenharias

Rua Gamaliel Martins Bezerra, 587. Alto da Alegria

59515000 - Angicos, RN-Brasil

Resumo: O processo de ensino-aprendizado passa por mudanças constantes, para acompanhar as diferenças e incrementos de metodologias e ensino mais atualizadas. As metodologias atuais tiram o aluno da posição de passivo, e os colocam na posição de ativo. Nesse contexto, este artigo possui o objetivo de relatar a experiência de uma metodologia de ensino-aprendizagem baseada na simulação de produção de envelopes, envolvendo alunos do curso de Engenharia de Produção de uma universidade pública. A dinâmica foi utilizada para difundir conceitos específicos de uma disciplina que abordava o conteúdo do Sistema Toyota de Produção e, por isso, a simulação de produção de envelopes de forma empurrada e puxada (com cartões kanban) foi utilizada. Não apenas pela maior interação entre discente e docente, mas também pela clareza com que o conteúdo foi assimilado pelos envolvidos, a prática foi concluída com sucesso. Isso pode ser visto pelos relatórios finais e notas dos estudantes, entregues com êxito.

Palavras-chave: Ensino. Aprendizado. Engenharia de Produção. Dinâmicas. 


\section{INTRODUÇÃO}

Há pelo menos 20 anos já se discutia a questão do aprendizado nas universidades, considerando a geração de profissionais ultrapassados, partindo da utilização de instrumentos de avaliação, e da falta de capacidade de renovação dos conhecimentos (DEMO, 1999). O profissional atual ainda é do tempo, não muito distante, em que se acreditava que o dever do aluno, em sala de aula, era escutar o professor, armazenar conteúdos, fazer provas e obter notas acima da média adotada na instituição. Isso acontecia ao invés de exercitar habilidades de aprendizagem.

Nesses ambientes em que o estudante atua apenas como receptor de informações e conteúdo no processo de aprendizagem, é muito difícil que venham a ser desenvolvidas habilidades de interpretação, raciocínios espaciais e lógicos, interpretação de desenhos, gráficos e imagens, além de síntese de informações e argumentação (ELMÔR FILHO et al., 2019). Mas a profissão moderna da engenharia inclui uma grande diversidade de conhecimentos, competências, funções exercidas e posicionamentos profissionais, diferentes dos representados pela antiga, mas ainda utilizada, aprendizagem passiva. $\mathrm{O}$ ensino nas engenharias requer ainda mais cuidados no que concerne os quesitos de aprendizagem. Isso porque, em sua maioria, é um curso que não forma professores, mas confere atribuições profissionais para tal (PEREIRA; BAZZO, 1997).

A engenharia é uma área de conhecimento que se destaca pela criação, geração, aperfeiçoamento e emprego de tecnologias visando a produção de bens de consumo e de serviços direcionados para atender as necessidades da sociedade. Nesse cenário, a utilização de estratégias e métodos de aprendizagem ativa passam a ser consideradas para atender as expectativas relativas ao perfil e habilidades buscados pelo mercado (ELMÔR FILHO et al., 2019) que, em geral, são completamente dinâmicos e, os cursos de engenharia estão em constante transição, modificando suas estruturas didático pedagógicas e buscando se adaptar às tendências de evolução global (LAURA; ARAÚJO, 2018).

O profissional de engenharia é formado dentro da instituição de ensino e solidifica seus conhecimentos a partir da prática diária de sua atividade profissional, e muitos dos conhecimentos adquiridos terão que ser esquecidos para darem lugar a outros, mais atualizados e condizentes com o mercado.

O presente trabalho trata de um relato de experiência de uma metodologia de ensinoaprendizagem baseada na simulação de produção de envelopes, envolvendo alunos do curso de Engenharia de Produção de uma universidade pública. Assim, está organizado da seguinte forma: esta seção de caráter introdutório com descrição do problema e objetivo, as seções 2 e 3 com breve relato teórico sobre o processo de aprendizagem e as dinâmicas para o ensino, a seção 4 com a descrição do procedimento de pesquisa, a seção 5 com a discussão dos resultados e, por fim, a seção de conclusões.

\section{O PROCESSO DE APRENDIZAGEM}

O processo de conhecimento é a interação específica do sujeito que se conhece e do objeto do conhecimento. Isso significa que em um processo de aprendizagem há sempre o sujeito, ou seja, aquele que se destina a aprender algo, e o objeto do conhecimento, ou seja, aquilo que será ensinado, e aprendido pelo sujeito. Por isso, em todas as análises do processo de conhecimento, três elementos básicos aparecem: o sujeito $(\mathrm{S})$ que se conhece, o objeto $(\mathrm{O})$ do conhecimento e o conhecimento como produto do processo cognitivo (PEREIRA; BAZZO, 1997). Mas nem 
sempre a relação entre sujeito e objeto acontece nessa ordem. Por isso, os autores Pereira e Bazzo (1997) citam três modelos existentes no processo de aprendizagem, conforme ilustrado na Figura 1.

Figura 1

\begin{tabular}{|ccc|}
\hline EMPIRICISMO & IDEALISMO & CONSTRUTIVISMO \\
$\mathbf{S} \leftarrow \mathbf{0}$ & $\mathbf{S} \rightarrow \mathbf{0}$ & $\mathbf{S} \leftrightarrow \mathbf{0}$ \\
\hline
\end{tabular}

Fonte: adaptado de Pereira e Bazzo (1997)

O primeiro modelo relatado pelos autores é o empiricismo. O empiricismo é a corrente da filosofia que considera a experiência como fonte única do conhecimento, propondo explicar os conceitos e juízes universais mediante a experiência pura (VON LINSINGEN; PEREIRA; BAZZO, 1999). No processo de aprendizagem, esse modelo é visto como um modelo mecânico, onde o sujeito do conhecimento é passivo, neutro e contemplativo, sendo apenas influenciado e moldado pelas verdades que emanam do objeto que a ele é apresentado. No ensino, o professor é considerado o elemento da ação, enquanto o aluno é o produto a ser trabalhado.

O segundo modelo relatado vê o sujeito como um elemento predominantemente atuante, comandando as suas ações. É o modelo idealista e ativista. O objeto, no caso o conhecimento, sofre a ação do sujeito, sendo estudado e entendido por ele. Cabe ao indivíduo sujeito, identificado como o aluno, criar a realidade corretamente, modificando-a quando achar que deve, para construir algo absoluto. Nesse modelo, a interação professor-aluno se transforma no modelo real de ensino-aprendizagem, com a organização concomitante de ritmos e interesses.

No terceiro modelo, que recebe o nome de interacionista ou construtivista, a relação entre sujeito e objeto, é vista sob ponto de vista da construção mútua, onde nenhum deles é neutro. Ao contrário, professor e aluno mantém a inter-relação entre seus elementos. Ocorre uma interpretação mútua entre ambos, onde o primeiro também aprende no decorrer da ação e o segundo aprende para si e também participa do crescimento do professor. O acontecido entre sujeito e objeto se vale do fator interação entre eles.

A escolha entre esses modelos, de forma consciente ou não, implica consequências importantes para a atuação pedagógica. Na maioria das instituições de ensino, o modelo de ensino-aprendizagem presente mais se assemelha ao modelo do empiricismo, no qual o professor atua como agente da ação e irá passar os seus conhecimentos para as mentes dos alunos. O modelo construtivista, que, aparentemente, possui uma tendência mais moderna no ensino, possui em sua essência a intenção de contextualizar o conhecimento a ser construído com o aluno, considerando-o como ser pensante.

Talvez, o motivo para que os modelos de ensino-aprendizagem ainda não tenham chegado à modernidade esperada esteja relacionado às abordagens e questionamentos relativos aos sistemas de avaliação. Estes, quando realizados, são feitos de forma imediatista, e para isso, a forma mais responsiva é o modelo padrão e mais comum de prova escrita, com questionamentos básicos acerca do conteúdo repassado ao aluno, o qual terá que responder de forma mais semelhante possível ao que estava nos livros, apostilas e materiais repassados e/ou indicados pelos professores. Para atender positivamente ao sistema de avaliação, o aluno precisa pensar exatamente da mesma forma que o professor (ou materiais por ele indicados e repassados) traz o conteúdo. Sendo assim, o aluno não tem oportunidade, naquele momento, de também construir o conhecimento. 
É importante perceber que os modelos de ensino-aprendizagem propostos por Pereira e Bazzo (1997), são percebidos como um sistema, no qual há interação entre dois agentes. A visão sistêmica é aquela proposta por Bertalanffy que considera que um sistema é um conjunto de componentes interagentes e interdependentes com objetivo comum (BERTALANFFY, 2008). Na situação de ensino-aprendizagem, aluno e professor são componentes desse sistema, que possui como objetivo comum, o conhecimento.

Passa-se então, a pensar no quesito qualidade de ensino. O que seria qualidade de ensino? Tem-se razões para acreditar que qualidade de ensino não se faz apenas com laboratórios bem equipados, informatização da burocracia universitária, bibliotecas climatizadas, salas de aulas limpas ou pessoas educadas atendendo nos balcões (PEREIRA; BAZZO, 1997). Essas são condições que, de fato, facilitam e ajudam o processo de ensino. Um ensino só pode ser considerado de qualidade se ele oportunizar a construção do conhecimento por todos os indivíduos envolvidos no processo.

\section{A UTILIZAÇÃO DE DINÂMICAS NO ENSINO DA ENGENHARIA}

O processo de conhecimento é a interação específica do sujeito que se conhece e do objeto do conhecimento. É importante valorizar atividades de aprendizagem e que os conceitos possam ser abordados e desenvolvidos a partir de investigações baseadas no bom senso, com uma experiência realmente possível de ser vivenciada (ELMÔR FILHO et al., 2019).

Não recentemente a aplicação de dinâmicas para a melhoria do aprendizado já vem acontecendo em diversas áreas da engenharia. Santos et al. (2014) relatam o caso na engenharia metalúrgica, no qual o aprendizado acontece durante os experimentos, por meio de um "modelo de caixa fechada". Também já foi relatado por Bressane et al. (2017) na engenharia ambiental, por meio da elaboração de propostas, diante de demandas do mercado de trabalho. Há relatos na engenharia de produção com a "Dinâmica do Barco" (WASQUEVITE, et al., 2017), com os blocos de montagem da LEGO® (SANTOS et al., 2014), com aviões de papel (BILLINGTON, 2004) e ainda conexões de PVC (SANTOS; GOHR; VIEIRA JUNIOR, 2012).

Alguns dos estilos e exemplos utilizados de dinâmicas em sala de aula, já fazem parte de uma literatura fixada e difundida. Fala-se em Dinâmica de Realidade Simulada (DRS) (BRESSANE et al., 2017), que consiste em uma estruturação metodológica que visa contribuir para a formação integral em cursos de caráter tecnológico, como as engenharias. A autora complementa a informação que, na DRS, o problema (cenário) é previamente concebido pelo professor e posteriormente apresentado aos alunos, tal como ocorre na Aprendizagem Baseada em Problemas, do inglês Problem-Based Learning - PBL, outra metodologia que envolve casos práticos no aprendizado.

Com as propostas de modificações atuais nos currículos dos cursos de engenharia, com a adoção das novas Diretrizes Curriculares Nacionais - DCNs, é possível que as diferenças entre as metodologias de dinâmicas se apresentem nas suas formulações, com orientação nos currículos. Esse é o caso da metodologia PBL, que se constitui em uma proposta que direciona toda a organização curricular, incluindo a concepção dos conteúdos programáticos e planos de ensino de modo integrado (BRESSANE et al., 2017). Mesmo com essas diferenças, todas elas se mostram como metodologias construtivistas, como ferramentas facilitadoras no processo de ensino e aprendizagem.

Em relação aos procedimentos para que as dinâmicas ocorram, a maioria dessas práticas relatam essa organização. São momentos distintos durante o mesmo semestre letivo, que passam, inicialmente, por uma abordagem teórica, sendo finalizada pela elaboração de 
relatórios a partir da observação dos alunos durante a prática (SANTOS et al., 2014). Outros condutores relatam sobre fases da prática, incluindo uma fase prévia, que envolve ações de planejamento para a concepção da abordagem pelo professor para os alunos, e uma fase executiva, com a apresentação do conteúdo aos alunos, a proposição da prática, a preparação dos alunos e, enfim, o desenvolvimento da dinâmica (BRESSANE et al., 2017).

Os relatórios finais servem como uma forma de avaliação. Os estudantes precisam mostrar o que aprenderam, com produções criativas, relevantes, que explicitem a evolução e o percurso realizado, visando uma ativa participação (ELMÔR FILHO et al., 2019).

\section{MÉTODO DE PESQUISA}

O método de pesquisa adotado neste trabalho classifica-se como estudo de caso com abordagem qualitativa visto que se trata de um relato de experiência do processo de ensinoaprendizagem com alunos do curso de Engenharia de Produção de uma universidade pública. Um estudo de caso surge do desejo de entender fenômenos sociais complexos, permitindo aos pesquisadores uma visão do mundo real (YIN, 2015).

Essa seção tem o intuito de relatar aspectos do procedimento da pesquisa, ou seja, de como este trabalho analisou o estudo de caso, e explicar detalhadamente os procedimentos da dinâmica realizada, como um processo de ensino-aprendizagem. Os dois aspectos relatados permitirão aos leitores compreenderem as análises sob o ponto de vista de educação na engenharia, e também traz um passo-a-passo, para possível orientação em caso de uso da dinâmica.

\subsection{Procedimentos da pesquisa}

A metodologia foi utilizada durante uma disciplina específica de Engenharia de Produção, que tinha como conteúdo principal as ferramentas e técnicas do Sistema Toyota de Produção. A disciplina tinha como principais participantes, alunos do oitavo semestre (quarto ano) do curso, ao qual exige-se um nível de conhecimento de conceitos e termos técnicos relativamente alto, considerando que os alunos já passaram pela maioria de disciplinas básicas do curso. A dinâmica desenvolvida teve seu foco na simulação do Sistema Kanban durante a simulação de um processo produtivo de envelopes.

Os relatos foram realizados pelo próprio professor por meio de observações diretas durante a dinâmica e também após, com os relatórios entregues pelos alunos, e as notas.

\subsection{Procedimento da dinâmica}

A disciplina teve seu curso comum com três unidades, nas quais as duas primeiras foram de aulas expositivas, com foco no professor. As aulas teóricas aconteceram por meio de slides, buscando a interação com os alunos esporadicamente, e ao fim, avaliação com prova escrita individual. A terceira unidade, que teve foco no conteúdo de Sistema Kanban, aconteceu com uma rápida exposição da teoria também em slides, para que os alunos tivessem uma ideia dos conceitos principais, dos tipos de cartões Kanban, e de seu funcionamento e, após isso, a avaliação por meio da dinâmica.

Antes da simulação do processo produtivo, houve o planejamento da disciplina, e alguns procedimentos foram estabelecidos (Figura 2), e repassados aos alunos. Inicialmente, houve apresentação de uma espécie de "Manual de Instruções", que traria informações sobre a dinâmica (Etapa 1) e sobre o processo produtivo (Etapa 2) com a explicação sobre as rodadas de produção. A produção aconteceu em três rodadas, com formatos de produção diferentes. 
Figura 2 - Procedimentos da dinâmica

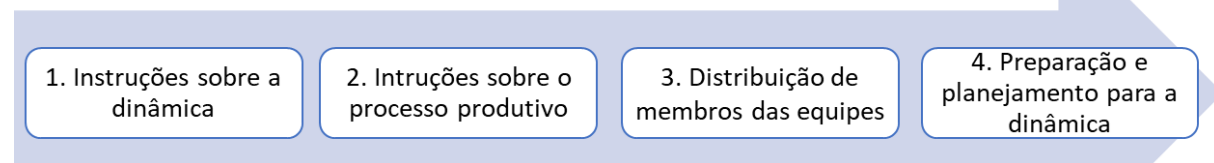

Fonte: elaboração própria (2020)

A primeira rodada, com o primeiro formato de produção, seguiu o estilo de "Produção Empurrada", na qual os alunos produziram envelopes continuamente, para estoque, durante um tempo previamente determinado. A segunda rodada, simulando uma "Produção Puxada", aconteceu com uma produção de lote unitário, ou seja, apenas uma unidade de envelope foi produzida. Já a terceira rodada, simulando também a "Produção Puxada", foi realizada com a produção de envelopes em lotes de três unidades, obedecendo a necessidade da demanda e sendo controlada por cartões Kanban. O objetivo de produzir em três formatos, era de que os alunos visualizassem formas de produção diferentes e ainda utilizados pelas fábricas atualmente, para que depois, percebessem as semelhanças e/ou diferenças entre eles.

No "Manual de Instruções" também continham orientações acerca do relatório final a ser entregue, com duas tabelas (Figura 3 e Figura 4) que deveriam ser preenchidas com as informações do processo produtivo. Esses instrumentos auxiliaram na comparação entre os sistemas de produção.

Figura 3 - Tabela de resultados

\begin{tabular}{|lllll|}
\hline & Risco & Corte & Dobra Cola Limpeza & Tempo Total \\
\hline Estoque & & & & \\
processo & & & & \\
Tempo 1 & & & & \\
Tempo 2 & & & & \\
Tempo & & & & \\
Médio & & & & \\
\hline
\end{tabular}

Fonte: dados da pesquisa
Figura 4 - Tabela de características

\begin{tabular}{|cccc|}
\hline \hline & $\begin{array}{c}\text { Produção } \\
\text { Empurrada }\end{array}$ & $\begin{array}{c}\text { Produção } \\
\text { Puxada }\end{array}$ & $\begin{array}{c}\text { Produção } \\
\text { Puxada/Kanban }\end{array}$ \\
\hline Fluxo Contínuo & & & \\
Takt Time & & \\
Manutenção TPM & & \\
Arranjo Físico & & \\
Multifuncionalidade & \\
Estoque & \\
Defeitos & \\
\hline \hline
\end{tabular}

Fonte: dados da pesquisa

As instruções acerca do processo produtivo também abarcavam as etapas do método de produção (Risco-Corte-Dobra-Colagem-Limpeza), o modelo do envelope (padrão básico), as matérias primas e ferramentas (papel, cola, molde, lápis/lapiseira, apontador, tesoura, borracha e cronômetro) com seus respectivos preços, os operadores e suas funções, e as possibilidades de layouts a serem utilizados no processo. As Figuras 5 e 6 ilustram, respectivamente, o catálogo de matérias primas e preços e, os layouts possíveis para o processo produtivo.

Figura 5 - Catálogo de materiais e preços

\begin{tabular}{|ll|}
\hline -Molde (uni) & $\mathrm{R} \$ 7,00$ \\
-Papel (uni) & $\mathrm{R} \$ 0,01$ \\
- Lápis (uni) & $\mathrm{R} \$ 0,30$ \\
-Lapiseira (uni) & $\mathrm{R} \$ 1,50$ \\
-Apontador (uso) & $\mathrm{R} \$ 0,50$ \\
- Tesoura tradicional (uni) & $\mathrm{R} \$ 3,00$ \\
- Tesoura ergonômica (uni) & $\mathrm{R} \$ 5,00$ \\
-Cola líquida (uni) & $\mathrm{R} \$ 1,50$ \\
-Cola bastão (uni) & $\mathrm{R} \$ 2,50$ \\
-Borracha (uni) & $\mathrm{R} \$ 1,00$ \\
\hline
\end{tabular}


Figura 6 - Possibilidades de layouts para o processo produtivo

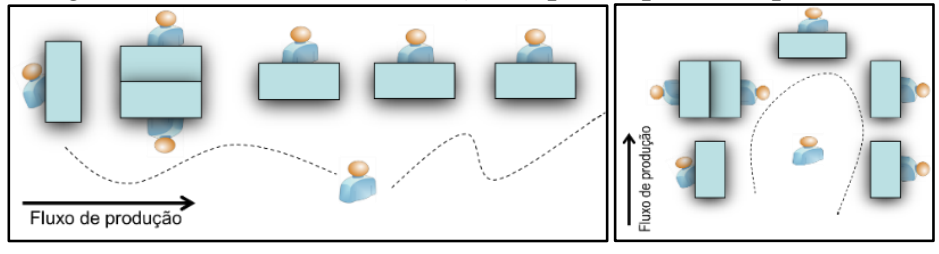

Fonte: dados da pesquisa

$\mathrm{Na}$ Etapa 3 dos procedimentos, sobre distribuição dos membros das equipes, os alunos foram divididos em equipes de setes componentes. No caso relatado, a turma contava com 42 alunos, sendo, portanto, dividida em seis grupos. A dinâmica aconteceu em dois dias de aulas, dividindo a turma na metade, para que as equipes tivessem espaço físico suficiente, especialmente para trabalhar com os layouts escolhidos, e melhor acompanhamento do professor.

$\mathrm{Na}$ Etapa 4, de preparação e planejamento da prática, os alunos planejaram o funcionamento da produção, desde a escolha dos materiais necessários (de acordo com o catálogo), calculando os custos básicos de matéria prima para a produção de envelopes, como também a escolha do layout de produção, a necessidade de operador para cada estação de trabalho. Algumas equipes desenvolveram uma rodada de produção "teste" para assegurar as escolhas e os melhores operadores para cada função. Nessa etapa as equipes receberam os cartões Kanban que seriam utilizados nas rodadas de produção puxada. Vale salientar que os cartões Kanban foram confeccionados pelo professor da disciplina e entregues aos alunos. A Figura 7 ilustra os cartões Kanban utilizados.

Figura 7 - Cartões Kanban

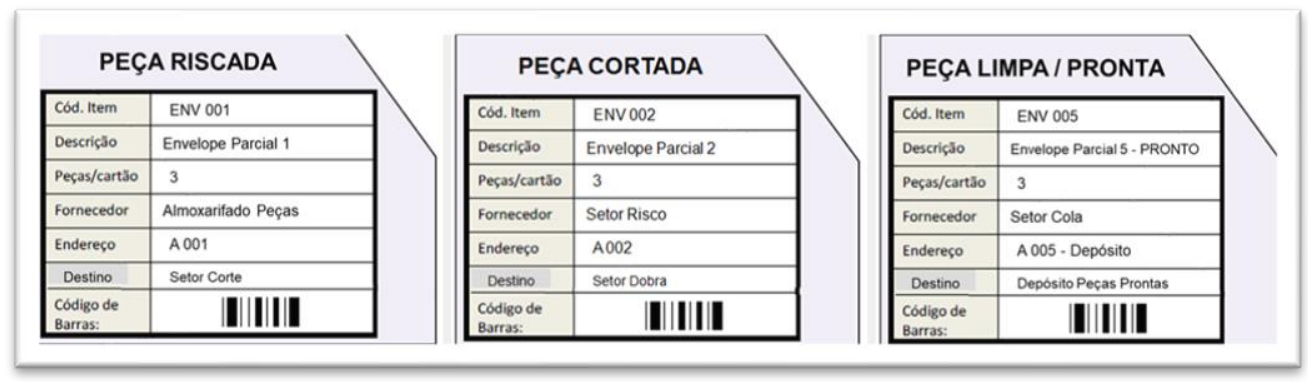

Fonte: dados da pesquisa

Pondo fim aos procedimentos de orientação da dinâmica e planejamento por parte das equipes, as rodadas de produção iniciaram. Um tempo padrão de $\mathrm{X}$ minutos foi estipulado para que a produção seguisse seu curso. Lembrando apenas do formato de produção da segunda rodada, que aconteceu em "Produção Puxada" com lote unitário. Para esta rodada, quando cada equipe finalizou o seu processo de produção de uma unidade de envelope, o tempo foi suspenso, e as equipes seguiram para a terceira rodada ao mesmo tempo.

Ao final do processo produtivo, o professor passou por cada equipe de produção, avaliando a qualidade dos envelopes produzidos. Isso aconteceu para que se buscasse um padrão de qualidade minimamente estabelecido e utilizado para todos. A informação dessa "inspeção de qualidade" foi repassada às equipes antes do início do processo. 


\section{RESULTADOS E DISCUSSÕES}

Ao final das rodadas de produção, as equipes tiveram um tempo para anotar seus resultados, e o relatório foi entregue na aula seguinte. Com o relatório analisado pelo professor, algumas discussões surgem, a saber:

A escolha das matérias primas e ferramentas, de acordo com o catálogo estabelecido, influenciou nos melhores tempos e resultados do sistema de produção. Essa é uma análise que pode acontecer diante da "bagagem" de conhecimento dos alunos, que já tinham visto conteúdos básicos do início do curso. As equipes que escolheram a matéria prima com menor valor financeiro, como por exemplo, a tesoura e o tipo de cola, teve produtos finais com menor qualidade. No caso da cola, a opção pela líquida, se usada sem o devido cuidado, gerava excedente, manchando o envelope, reduzindo a qualidade do produto final.

O método escolhido para algumas etapas, influenciou no tempo de processamento da peça. Isso aconteceu nas etapas RISCO e DOBRA/LIMPEZA, que podem ser vistas nas Figuras $8 \mathrm{e}$ 9. A Figura 8 mostra claramente a etapa do RISCO. Nessa equipe, eles optaram com encostar uma das laterais do molde na folha branca, e seguir o risco dali em diante. Essa ação evitou o corte de um lado, reduzindo o tempo de processamento. Já a Figura 9, mostra a etapa da LIMPEZA, que teve seu tempo reduzido em virtude do método de DOBRA, deixando no interior do envelope, os resquícios do RISCO, evitando fazer a limpeza com borracha em todos os lados do envelope, fazendo-a apenas nos lados visualmente expostos.

A escolha dos operadores mais adequados para determinadas funções, influenciou nos resultados do processo produtivo em relação ao tempo de processamento e a qualidade. Foi percebido pelo professor da disciplina, ainda durante a fase de teste das equipes, que algumas fizeram rodadas-testes com vários operadores em funções diferentes, inclusive, com tempos cronometrados. Nessa ação, além de perceber a atividade mais crítica, as equipes perceberam também as habilidades de cada operador. Isso foi de importância decisiva para ter o melhor desempenho final.

Vale salientar que as decisões tomadas pelas equipes, que influenciaram em alguns resultados do processo produtivo, foram pensadas pela própria equipe. Percebeu-se que isso foi possível por ter os alunos trabalhando em equipes, trocando ideias e compartilhando informações. É possível que uns tenham aprendido com os outros.

Figura 8 - Etapa de risco

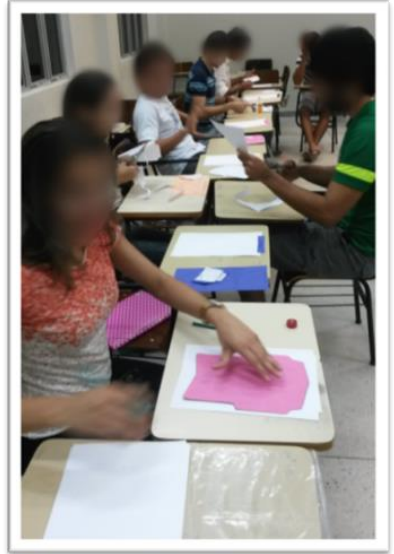

Fonte: dados da pesquisa
Figura 9 - Etapa de limpeza

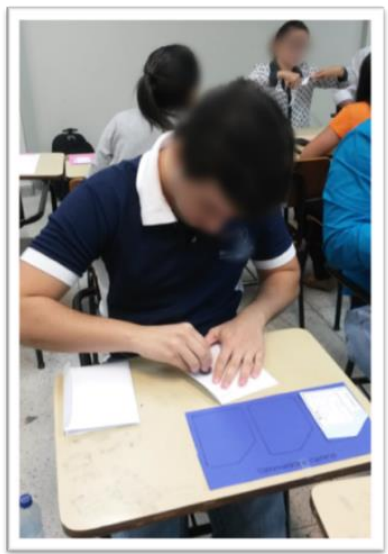

Fonte: dados da pesquisa 


\section{CONCLUSÕES}

Ao fim da análise da metodologia utilizada na disciplina como fonte de um aprendizado minimamente prático, percebeu-se a resposta positiva e o sucesso da prática, visto que o desempenho dos alunos, individualmente e em equipe, foi superior se relacionado às atividades padrões de prova escrita. Isso pode ser visto por meio das notas, e sucesso dos relatórios finais.

O resultado positivo da dinâmica também pode ser visto por meio da interação e motivação dos alunos durante as dinâmicas. Eles conversavam entre si de forma entusiasmada sobre as melhores ferramentas e condições dos processos produtivos.

Vale salientar que, em relação as limitações, este relato foi a primeira experiência do professor com aplicação de dinâmicas de produção de envelopes para simular figurativamente o sistema de produção kanban, então alterações são necessárias para aplicações futuras com o mesmo objetivo de conteúdo e também para outros conteúdos específicos da área de engenharia de produção.

Sugere-se também repetir a experiência outras vezes com outras turmas, para garantir o sucesso da prática em relação a um melhor nível e qualidade de aprendizado de conteúdos nos ambientes universitários.

\section{REFERÊNCIAS}

BERTALANFFY, Ludwig von. Teoria geral dos sistemas: fundamentos, desenvolvimento e aplicações. 2008.

BILLINGTON, P. J. A classroom exercise to illustrate lean manufacturing pull concepts. Decision Sciences Journal of Innovative Education, v. 2, n. 1, p. 71-76, 2004.

BRESSANE, A. et al. Aprendizagem baseada em dinâmicas: uma proposta pedagógica para formação integral na engenharia. Revista de Ensino de Engenharia, v. 36, n. 1, 2017.

DEMO, P. Educação e desenvolvimento: mito e realidade de uma relação possível e fantasiosa. Papirus, 1999.

ELMÔR FILHO, G. et al. Uma nova sala de aula é possível: aprendizagem ativa na educação em engenharia. 1. ed. Rio de Janeiro: LTC, 2019.

LAURA, T. L.; ARAUJO, P. R. O processo de ensino e aprendizagem baseada em projetos: relato de experiência na engenharia. In: Congresso Brasileiro de Educação em Engenharia, 2018, Anais. Salvador, 2018.

VON LINSINGEN, Irlan; PEREIRA, L.; BAZZO, W. Epistemologia e ensino de engenharia. Revista de Ensino de Engenharia, v. 18, n. 01, p. 51-57, 1999.

PEREIRA, L. T. V.; BAZZO, W. A. Ensino de engenharia: na busca do seu aprimoramento. Florianópolis: UFSC, 1997. 
SANTOS, L. C.; MIRANDA A. L.; DUTRA, J. B. Uma dinâmica para o ensino da matriz produto-processo: roteiro e aplicação. Revista Produção Online, v. 14, n. 3, p. 1129-1150, 2014.

SANTOS, L. C.; GOHR, C. F.; VIEIRA JUNIOR, M. Simulation of assembly operations using interchangeable parts for $\mathrm{OM}$ education: a hands-on activity with water pipe fittings. International Journal of Operations \& Production Management, v. 32, n. 12, p. 1427-1440, 2012.

WASQUEVITE, Guilherme et al. Dinâmica do barco: percepção da aprendizagem dos discentes do curso de engenharia de produção. Anais. Salão Internacional de Ensino, Pesquisa e Extensão, v. 9, n. 1, 2017.

YIN, Robert K. Estudo de Caso: Planejamento e métodos. Bookman editora, 2015.

\title{
THE USE OF DYNAMICS FOR TEACHING IN ENGINEERING: A REPORT IN INDUSTRIAL ENGINEERING
}

\begin{abstract}
The teaching-learning process undergoes constant changes, to keep up with the differences and increments in the most up-to-date teaching and methodologies. Current methodologies take the student out of the liability position and place them in the active position. In this context, this article aims to report the experience of a teaching-learning methodology based on the simulation of envelope production, involving students from the Production Engineering course at a public university. The case simulated concepts specific to a discipline that addressed the content of the Toyota Production System and, therefore, simulated production of envelopes in a pushed and pulled way (with kanban cards). Not only for the greater interaction between student and teacher, but also for the clarity with which the content was assimilated by those involved, the practice was successfully concluded. This can be seen from the students' final reports and grades, delivered successfully.
\end{abstract}

Keywords: Teaching. Learning. Industrial engineering. Dynamic. 